Turkay, S., \& Adinolf, S. (2015). The effects of customization on motivation in an extended study with a massively multiplayer online roleplaying game. Cyberpsychology: Journal of Psychosocial Research on Cyberspace, 9(3), article 2. doi: 10.5817/CP2015-3-2

\title{
The effects of customization on motivation in an extended study with a massively multiplayer online roleplaying game
}

\author{
Selen Turkay ${ }^{1}$, Sonam Adinolf ${ }^{2}$ \\ ${ }^{1}$ Harvard Initiative for Learning and Teaching, Harvard University, Cambridge, MA, United States \\ ${ }^{2}$ Massachusetts Institute of Technology, Cambridge, MA, United States
}

\begin{abstract}
Customization is a ubiquitous feature of games and can be perceived as a series of choices that may influence players' experiences. Opportunities for customization may give users decision-making authority over the technology, enabling them to shape and create their own experiences, as well as provide ways to be a part of a group based on their needs and desires. This study aims to shed more light on the effects customization has on players' motivation, and investigates how customization as a way of user control affects player motivation within an MMO. A mixed method study was designed with two conditions: customization $(n=33)$ and no customization ( $n=33$ ). Adult participants played Lord of the Rings Online (LotRO), a Massively Multiplayer Online game, for about ten hours over four sessions. Data was collected through surveys, interviews and observations. Results showed that players' desire to replay the game increased over time, and customization affected players' motivation positively. Findings are discussed through the lens of Self-Determination Theory (Deci \& Ryan, 1985).
\end{abstract}

Keywords: customization, motivation, MMOs, player retention

\section{Introduction}

Virtual worlds are immersive, simulated environments. They enable users to move and interact over the Internet through virtual bodies, called avatars. Virtual worlds are considered complex as they offer numerous activities for users (e.g., socializing, gaming, exploring, role-playing, etc.) and/or require consideration of several attributes (e.g., avatar appearance, character skills, navigating in the environment, enemies, etc.) with regard to user experiences (Bartle, 2003). Massively Multiplayer Online games (MMOs) are a type of gaming virtual world. MMOs are persistent, networked, and interactive environments, which support large numbers of people, either synchronously or asynchronously. MMOs also motivate players to play longer periods of time compared to other games $(\mathrm{Ng} \&$ Wiemer-Hastings, 2005).

MMO players' motivation and willingness to continue playing is encouraged by game design aspects such as challenge, fantasy, curiosity (Malone, 1981), narrative, character design (Dickey, 2007), feedback, clear goals and tasks, and by providing users ways to feel control in the virtual world (Przybylski, Rigby, \& Ryan, 2010; Rieber, 1996; Sweetsner \& Wyeth, 2005). These design aspects promote intrinsicallyrewarding behaviors that make player experiences more enjoyable and more likely to be repeated in the future (Csikszentmihalyi, 1975).

In many MMOs, the decision to continue to play may be related to player agency, such as the ability to control her character's actions and appearance in the game world (Ryan, Rigby, \& Przybylski, 2006). Desurvire, Caplan, and Toth (2004) put forward sense of control as one of the heuristics for playability and state, "Players should perceive a sense of control and impact onto the game world. The game world 
reacts to the player and remembers their passage through it..." (p. 1511). Therefore, players' sense of control is closely related to playability of games. Self Determination Theory (Deci \& Ryan, 1985), a metamotivation theory, suggests that autonomy is crucial for people's motivation, implying that if people feel control over an activity, they will feel more motivated to come back to do the same activity. Many design features such as feedback, challenge, choice and interactivity, are known to increase players' agency and sense of control (Grodal, 2000). Among these, choice is most closely tied with sense of control (Averill, 1973). When players have choices in the game, they feel both autonomy and decisional control in the game environment (Averill, 1973; Ryan et al., 2006).

Much is known about the effects of choice from motivational theories and cognitive studies. For example, Self Determination Theory (SDT) represents a broad framework for the study of human motivation and personality within social contexts. According to this theory, there are three basic psychological needs that, when satisfied, enhance intrinsic motivation (Ryan \& Deci, 2000). Those three needs are the need for autonomy, relatedness, and competence. The need for autonomy refers to the need to feel a sense of full volition and "choicefulness" regarding one's activities and goals. This feeling emerges when one's actions and goals are experienced as emanating from one's authentic self (Deci \& Ryan, 1985). A central focus in SDT on autonomy contributes to adaptive motivation and has been interpreted by many as the practice of providing choice (Iyengar \& Lepper, 1999).

A quick study of current digital games, especially MMOs, shows that these environments provide many different choices to their players. Often there are choices embedded within choices. In essence, such choices give users options to customize their experiences. Customization may satisfy players' need for autonomy, increase their sense of control over in the game world, and motivate them to come back to do the same activity.

Teng (2010) showed customization as an important feature for increasing MMO players' loyalty, implying that customization may affect player motivation towards a game since a player's loyalty to a game indicates enjoyment and motivation to play that game. In fact, a mixed method survey study conducted with 871 players from four major MMOs revealed that players enjoy customizing their games and this influences their overall enjoyment of the game (Turkay \& Adinolf, 2010a). There remains a lack of systematic empirical research on the effect of player's' ability to customize in a social context with relation to player motivation. While users are provided with more and more customization in their virtual world interactions, we need a comprehensive understanding of customizations on user experiences in virtual worlds.

In this study, the following operational definitions apply:

Motivation is the desire of a player to come back and play a game repeatedly.

Customization is a process that changes the functionality, appearance, or usability of a game through making decisions on various choices in an attempt to increase its personal relevance to the player.

In spite of the importance of long-term motivation to all virtual worlds, there is a dearth of research on how motivation evolves over time and how specific design aspects impact motivation in extended gameplay. It is this gap that this study aimed to fill. For this purpose, the following research question is posed.

RQ: How does customization impact player motivation over extended gameplay?

This study aimed to capture the evolution of players' motivation and the impact of customization on this evolution. Therefore, this study was conducted over a significant length of time (10 hours) and four play sessions.

\section{Motivation}

Motivation toward playing a game is indicated by a player's persistence and willingness to come back and put their time and energy into playing that game. In this sense, player motivation is related to loyalty, which can be viewed as a gamer's tendency to play a game repeatedly (Choi \& Kim, 2004; Teng, 2010). Gamer loyalty is important for game developers as it provides stable revenue for them and represents a business advantage (Reichheld \& Schefter, 2000). 
Novelty is one attribute of a game that can motivate players (Baranes, Oudeyer, \& Gottlieb, 2014). Experiencing novelty is enjoyable (Biederman \& Vessel, 2006) and it sustains users' attention (Pace, 2004). Novelty affects people's motivation to purchase videogames (Hsu, Lee, \& Wu, 2005). A recent study confirmed that seeking novelty, both in terms of interaction with new players and new information, could motivate players to a great extent (Hussain, Williams, \& Griffiths, 2015). However, game designers face a challenge of keeping players engaged when the novelty effect disappears. Some games provide new content via expansions to retain players (Stafford, Stafford, \& Schkade, 2004); others introduce different ways users can create content or customize their characters (Walther, van der Heide, Kim, Westerman, \& Tong, 2008). Taking the latter approach, an environment that maintains user interest in their online identities may encourage their return to the game's community. Customization, defined as a series of choices, is a common way for users to establish their online identities (Turkay \& Kinzer, 2014).

\section{Customization}

Customization plays a key role in video games and virtual worlds. MMOs offer players ways to customize their experiences, either through built-in options or the ability to create or obtain add-on software modules, as seen in games such as World of Warcraft (WoW; Blizzard, 2004) and Star Wars: The Old Republic (SWTOR; Bioware, 2011). They allow players to make custom user interfaces (Adinolf \& Turkay, 2011), and even create levels (e.g. Little Big Planet, Sony Computer Entertainment, 2008). Each option elected by the player makes the game look and feel different, which may significantly increase the retention rate (Holm, Havukainen, \& Arrasvuori, 2005). Customization in MMOs can be grouped into three broad categories (Turkay \& Adinolf, 2010b, p. 1841; Marathe, 2007):

Functional customization: Customization that affects game mechanics and dynamics directly and therefore has a direct effect on individual player gameplay. Customizing character skills is an example of this type of customization.

Cosmetic customization: Customization that does not affect game mechanics and dynamics. Avatar customization is an example of this type of customization. Although it does not directly affect gameplay, it may affect a player's enjoyment of the game.

Usability: Customization that does not affect game mechanics and dynamics directly but may affect player performance, such as interface customization. It may have an effect on players' gameplay experience.

Studies have examined customization as a mechanism to foster motivation in games, and investigated its effect or importance to users in relation to other engagement attributes or game features. Yee (2006) found that choices concerning appearance, accessories, and color scheme in games were important subcomponents of MMO player motivation. Turkay and Adinolf (2010b) showed that sense of control and customization are highly correlated and valued by players. Studies with non-MMO games showed similar results. Cordova and Lepper (1996) found that even trivial choices such as picking the color of a vehicle to customize a game could boost players' motivation. Relatedly, Kinzer et al.'s (2012) study showed that providing choices of non-player characters increased players' motivation. Customization might have made the games more meaningful to the players and led them identify more closely with the game and "take ownership" of it (Ondrejka, 2004).

One of the most important aspects of virtual worlds is that they are avatar-based. Avatars have been a crucial feature of digital games and online environments since their inception, due to their representations of players in these online worlds (Turkle, 1995; Turkay \& Kinzer, 2014). Many games allow avatar customization to some extent. In fact, it is a main form of customization in many MMOs. Players spend considerable amounts of time customizing appearance and abilities of their game characters (Ducheneaut, Wen, Yee, \& Wadley, 2009; Turkay \& Kinzer, 2014). Fischer, Kastenmüller and Greitemeyer (2010) found that avatar customization can amplify the psychological effects of video games through increased identification with one's character, and, in turn, may increase game enjoyment and time spent within a virtual world (Bailey, Wise, \& Bolls, 2009; Klimmt, Hefner, \& Vorderer, 2009; Trepte \& Reinecke, 2010). With all this in mind, our hypothesis is:

H1: Customization will lead to increased motivation. 


\section{Methods}

\section{Participants}

Adult participants were recruited through fliers at a medium-sized private East Coast University in the US, and were remunerated $\$ 50$ ( $\$ 5$ per hour) for their time. Interested individuals filled out a pre-survey designed to gather demographic information and gaming experiences. Those who had availability for an extended study, and who were neither experienced nor current MMO players, were invited to participate in the study. The participants' average age was $25.86(S D=4.29)$, which is close to the average age of MMO players $(M=26.6)$ as reported in a previous, large scale study (Yee, 2006).

MMOs are long-term games and a reliable study of player behavior in these games should take place over more than one experimental session. To approximate voluntary gameplay (see Ducheneaut, Yee, Nickell, \& Moore, 2006; Mahmassani, Chen, Huang, Williams \& Contractor, 2010), this study's procedure involved about 10 hours of game play, which was divided into 4 sessions over two weeks.

\section{Instruments and Stimulus}

We adapted O'Brien and Toms' (2010) engagement scale to measure players' engagement in the study. The original instrument consisted of 31 items with six attributes and was developed to measure user engagement in a variety of online tasks including gaming. For the context of the current paper, we are interested in items measuring novelty ( 3 items) and perceived playability (6 items) as they relate to player motivation. Cronbach's a for these factors were .80 or higher. We measured players' sense of control with a single item, "I felt in control of my gaming experience." Game motivation as operationalized in this paper was assessed with a single 7-point Likert scale item, "I would be willing to play this game again", taken from the Intrinsic Motivation Inventory (IMI; Ryan, Mims, \& Koestner, 1983).

Semi-structured interviews were conducted after gameplay sessions to collect qualitative data.

Lord of the Rings Online (LotRO, Turbine, 2007) was chosen as the stimulus for this study. It is a representative of a fantasy MMO and offers several ways for players to customize their experiences including cosmetic (e.g., being able to purchase dresses for purely aesthetics purposes) and functional customization (e.g., choices for different character skills). Playing a game based on a well-known novel was also thought of as an advantage for novice players.

\section{Design}

A between-subjects design was used to collect data. Participants were randomly assigned to one of two groups by gender, Customization (CG) $(n=33 ; 17$ females) and No Customization (NCG) $(n=33 ; 17$ females).

No statistically significant difference was found between groups in their average age $(t=.72, p>.05)$. Likewise, there was no statistically significant difference between groups in their experience with MMOs ( $t$ $=1.32, p>.05$ ). A Lord of the Rings (LotR) familiarity score was generated based on participants' reports on how familiar they were with Lord of the Rings in various media forms (i.e., books, movies, card games, videogames). No statistically significant difference was found $(t=0.944, p>.05)$. Based on these results, the groups were assumed equal at the beginning of the study, and statistical tests were run without consideration of the impact of these variables on the dependent variables.

\section{Data Analysis}

Independent samples $t$-tests were conducted to test differences between CG and NCG per session on dependent variables. Assuming the normality of the data, RM-ANOVA was conducted to test for a possible difference between the CG and NCG participants in the effect of change in their ratings on their motivation scores. The following assumptions were tested: (a) independence of observation, (b) normality, and (c) sphericity. Pearson correlations were conducted to test the direction and strength of a relationship between motivation, perceived playability and perceived control. Independence of observation and normality were met. The assumption of sphericity was violated for both analyses. Thus, the GreenhouseGeisser epsilon was used to correct degrees of freedom. 
Interviews were transcribed and coded by the authors. The coded segments were subjected to inter-coder reliability by an independent coder. Final agreement percentage was $92 \%$.

\section{Procedure}

Individuals in this study participated in four sessions, which summed up to about 10 hours. In the first session, CG created their game characters and customized their appearance. The average time spent on character creation was twelve minutes and 23 seconds. On average, participants spent six minutes and 43 seconds on race and class selection and five minutes and 39 seconds on avatar appearance and name selection. NCG were assigned well-made, pre-generated characters that matched each participant's gender. Participants continued to play with their character throughout the study. For both groups, the first session ended upon completion of the LotRO tutorial (which takes about 2 to 2.5 hours). At the end of each game session, participants completed surveys on the computer.

CG participants were introduced to various ways they could customize in the game. NCG participants' choices were controlled. For example, NCG did not choose their mission rewards; the researcher chose for them, binding keyboard shortcuts for that purpose. NCG participants were told that the computer would make the reward choices for them until they learned the game. During the study, participants had no line of sight to the researcher. This allowed smooth control of NCG's choices. NCG's characters' appearance were fixed using the cosmetic outfit option in LotRO, so that participants would see the same outfit no matter how their characters were equipped throughout the sessions. These differences aimed to control CG's and NCG's autonomy and control by dictating their customization options.

\section{Results}

\section{Motivation: Willingness to Replay the Game}

Independent samples $t$-tests revealed statistically significant differences between CG and NCG in their willingness to replay the game at the end of each session (see Table 1).

RM-ANOVA revealed a statistically significant medium size main effect of time (number of play sessions), $F(2.63,165.92)=18.868, p<.001$ (motivation significantly changed over time), $\eta_{\text {partial }}^{2}=.23$ and of customization, $F(1,63)=22.36, p<.001, \eta_{\text {partial }}^{2}=.26$ (customization had a medium size effect on people's motivation levels). There was no significant interaction between groups and sessions, $F(2.63$, $165.92)=1.55, p>.05$.

Table 1. Means and Standard Deviations of the Motivation Scores.

\begin{tabular}{lccccccc}
\hline Sessions & \multicolumn{3}{c}{ Independent Samples } & \multicolumn{3}{c}{ CG } & \multicolumn{3}{c}{ NCG } \\
& \multicolumn{3}{c}{ t-test } & & & & \\
& $t$ & $p$ & $\eta^{2}$ & $M$ & $S D$ & $M$ & $S D$ \\
Session 1 & -3.20 & .002 & .14 & 5.66 & 1.43 & 4.36 & 1.80 \\
Session 2 & -2.93 & .005 & .12 & 4.59 & 1.32 & 3.52 & 1.62 \\
Session 3 & -3.61 & .001 & .17 & 5.87 & 1.21 & 4.64 & 1.58 \\
Session 4 & -4.85 & .000 & .27 & 5.06 & 1.44 & 3.18 & 1.72 \\
\hline
\end{tabular}

Tests of Within-Subjects Contrasts showed a statistically significant linear $F(1,63)=5.12, p<.05$, $\eta_{\text {partial }}^{2}=.08$ and cubic relationship $F(1,63)=47.03, p<.001, \eta_{\text {partial }}^{2}=.43$ between sessions and the motivation to play the game. Cubic relationship indicates that players' motivation changed direction multiple times throughout their gameplay sessions (see Figure 1). A set of additional Within-Subject Contrast tests showed the differences between sessions in players' willingness to replay the game (see Table 2) 
Table 2. Test of Within-Subjects Contrasts for Motivation.

\begin{tabular}{lcccc}
\hline & SS & $\boldsymbol{F}$ & Sig. & ${\text { Partial } \boldsymbol{\eta}^{\mathbf{2}}}$ \\
\hline Session 1 vs. Session 2 & 59.33 & 16.39 & .000 & .21 \\
Session 2 vs. Session 3 & 93.77 & 41.03 & .000 & .39 \\
Session 3 vs. Session 4 & 83.50 & 40.76 & .000 & .39 \\
Session 1 vs. Later (Mean 2, 3, 4) & 18.43 & 8.04 & .006 & .11 \\
Session 2 vs. Later (Mean 3, 4) & 26.16 & 15.42 & .000 & .20 \\
Session 3 vs. Previous (Mean 1, 2) & 34.02 & 25.52 & .000 & .29 \\
Session 4 vs. Previous (Mean 1, 2, 3) & 27.56 & 17.66 & .000 & .22 \\
\hline
\end{tabular}

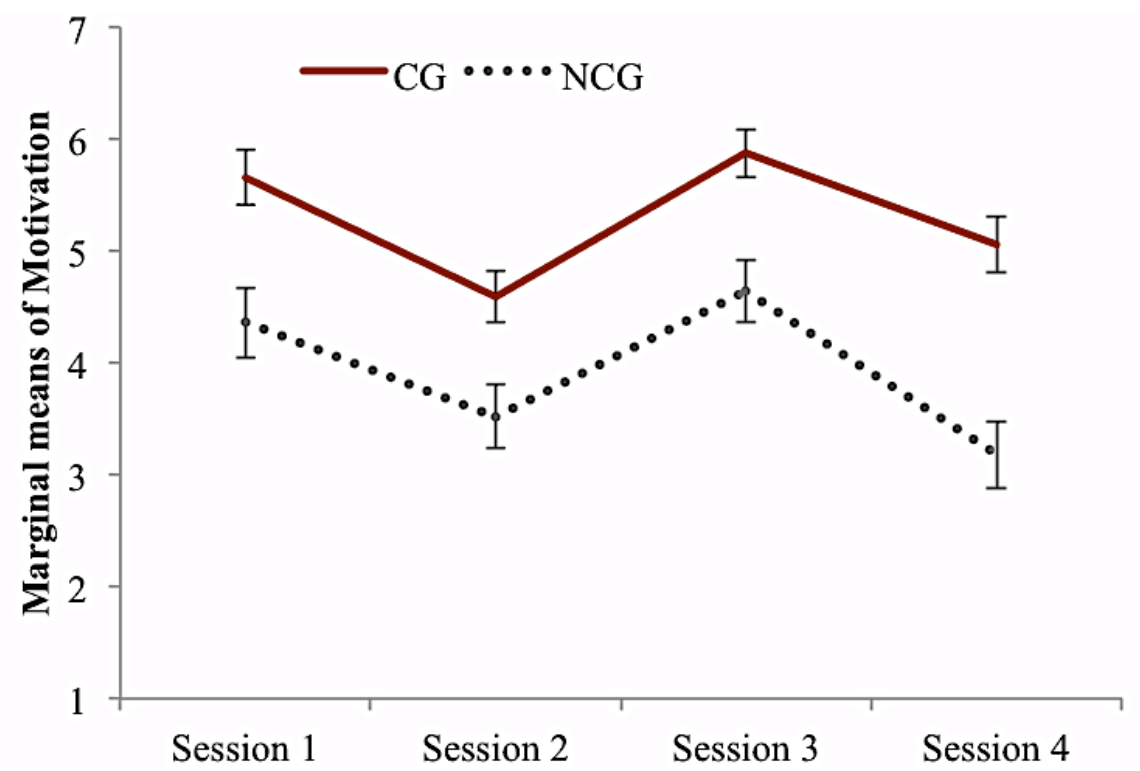

Figure 1. Marginal estimated means of Motivation over four sessions.

\section{Predictors of Motivation}

A follow-up question we asked is to what extent we can predict whether a player would be willing to replay based on their in-game experiences. For each session, a two stage hierarchical multiple regression was conducted with motivation as the dependent variable. Customization (a dummy variable; coded as 0 = no customization; 1 = customization) was entered at stage one of the regression to control for the experimental groups. Game experience variables, Playability/Usability, Novelty, and Perceived Control were entered at stage two (see Table 3 ). All correlations between the multiple regression variables are reported in Tables A1-A2-A3-A4 in the Appendix. Correlations between the predictor variables and the dependent variable were weak to moderately strong.

For session 1, the hierarchical multiple regression revealed that at stage one, customization contributed statistically significantly to the model, $F(1,63)=10.25, p=.002$ and explained $14 \%$ of the variance in participants' motivation (see Table A5 in the Appendix for details). After entering other predictors at Step 2 , the total variance explained by the model as a whole was $44 \%, F(4,60)=11.89, p<.001$. Introduction of the additional variables explained an additional 30\% variance in player motivation, after controlling for the experimental condition. In the final model, three predictor variables were statistically significant: customization, $\beta=.24, p=.025$, novelty, $\beta=.44, p<.001$ and perceived playability/usability, $\beta=.32, p=.016$. 
For session 2, the first model was statistically significant, $F(1,64)=8.59, p=.005$ and explained $12 \%$ of the variance in participants' motivation (see Table A6 in the Appendix for details). After entering other predictors at Step 2, the total variance explained by the model as a whole was $45 \%, F(4,61)=12.336, p$ $<.001$. Introduction of the additional variables explained additional $33 \%$ variance in player motivation, after controlling for the experimental condition. In the final model, only one predictor variable, novelty, was statistically significant, $\beta=.57, p<.001$.

For session 3, the first model was statistically significant, $F(1,64)=13.03, p=.001$ and explained $17 \%$ of the variance in participants' motivation (see Table A7 in the Appendix for details). After entering other predictors at Step 2, the model explained $54 \%$ of the variance, $F(4,61)=18.21, p<.001$. Introduction of the additional variables explained additional $37 \%$ variance in player motivation, after controlling for the experimental condition. In the final model, only statistically significant predictor variables were novelty, $\beta$ $=.45, p<.001$, and perceived control, $\beta=.33, p=.01$.

For session 4, the first model was statistically significant, $F(1,64)=23.48, p<.001$ and explained $27 \%$ of the variance in participants' motivation (see Table A8 in the Appendix for details). After entering other predictors at Step 2, the total variance explained by the model was $65 \%, F(4,61)=28.57, p<.001$. Introduction of the additional variables explained additional $38 \%$ variance in player motivation, after controlling for the experimental condition. In the final model, there were three statistically significant predictor variables: customization, $\beta=.25, p=.005$, novelty, $\beta=.51, p<.001$, and sense of control, $\beta$ $=.22, p=.035$.

Table 3. Means and Standard Deviation of Perceived Control, Novelty and Playability.

\begin{tabular}{lccccccccccccc}
\hline & \multicolumn{4}{c}{ Perceived Control } & \multicolumn{4}{c}{ Novelty } & \multicolumn{4}{c}{ Playability } \\
& \multicolumn{2}{c}{ CG } & \multicolumn{2}{c}{ NCG } & \multicolumn{2}{c}{ CG } & \multicolumn{2}{c}{ NCG } & \multicolumn{2}{c}{ CG } & \multicolumn{2}{c}{ NCG } \\
& $M$ & $S D$ & $M$ & $S D$ & $M$ & $S D$ & $M$ & $S D$ & $M$ & $S D$ & $M$ & $S D$ \\
\hline Session 1 & 3.30 & 0.81 & 3.49 & 0.84 & 3.49 & 0.84 & 2.94 & 0.89 & 3.34 & 0.65 & 3.30 & 0.60 \\
Session 2 & 3.27 & 0.88 & 3.53 & 0.83 & 3.53 & 0.83 & 2.88 & 1.11 & 3.25 & 0.78 & 3.10 & 0.50 \\
Session 3 & 3.64 & 0.93 & 3.70 & 0.87 & 3.70 & 0.87 & 2.85 & 1.07 & 3.33 & 0.68 & 3.17 & 0.54 \\
Session 4 & 3.76 & 0.71 & 3.82 & 0.86 & 3.82 & 0.86 & 3.06 & 1.01 & 3.65 & 0.58 & 3.15 & 0.60 \\
\hline
\end{tabular}

\section{Qualitative Findings}

Motivation: You had my curiosity, now you have my attention. In a lab study with a monetary incentive, it is challenging to study intrinsic motivations such as willingness to come back and play the game. For example, when participants were asked whether they would like to continue with the study after each session, they all said yes. However, as we saw earlier in this paper, this willingness seemed to fluctuate across different sessions, and NCG seemed to be less willing than CG. Interviews revealed some clues to what the reasons might be for the players' differing willingness to play the game.

In the first session, character customization was one of the facilitators of motivation for some CG participants, including [P37], "...I was curious. I spent some time customizing my character. In the end, since I customized my character I'm more interested in playing with this character and the winning battles with this character ..." Motivations for advancing the player's character through gaining new equipment or customizing avatar appearance was common across all the sessions, but especially in the fourth session.

A few participants $(n=7)$ talked about their curiosity to learn more about the game after the first session. Curiosity was also related to the game's novelty. Players wanted to come back to play because they wanted to unlock the part of the story or part of the map that they had not seen. For example, like [P23] from NCG, some were thinking "...where am I in the big picture?" and some, like [P62] from CG, were curious about the narrative "...I am curious about what will happen [with the story] because I traveled all the way to Thorin's Gate..." 
Many participants talked about achievement-related motivations. They wanted to play to overcome challenges they encountered unsuccessfully during a previous gameplay session. For some, it was to help an elderly character by rescuing her from bandits, for others it was to collect enough gold to buy a virtual horse or defeat a spider queen to save the village in the game.

The social aspect of the game proved to be increasingly motivational for one-third of the players (33\%) as they progressed through sessions. This was evidenced by participants' positive emphasis on this aspect while talking about their experiences. More players after the last session ( $C G=10, N C G=10)$ than the first session ( $C G=5, N C G=2$ ) said that they felt social in the game. Many players were not even aware of the existence of other player characters in the game world. One of these people was [P73] from NCG and when I asked him whether he felt social, he said, "Not quite. Probably because you need to hear people in your headset before you realize there is more social involvement. I wasn't aware that there were other people involved..." Some also reasoned that they might not have realized that there were other players during the first session because they were busy learning the game: "I wasn't really focusing on the communication part. I was focusing on what I needed to do and how to accomplish the task." (P31, CG) However, realizing the affordance of the game for socialization did not always mean that players would socialize. In fact, some players $(n=10)$ chose not to play with others. [P72] from NCG was one of them. He rejected a fellowship, a form of group play, requested from other players in the third session. When he was asked why he did not accept, he said he preferred experiencing the story rather than social play.

Motivation-related comments increased from the first interview $(n=21, \mathrm{CG}=8)$ to the last one $(n=37$, CG $=22$ ). Players also reported being more motivated as they played more. A representative quote, [P19] "... I was more drawn into it as I played more. Also definitely I started looking at different maps and seeing that the world included all different places in the Middle Earth was very exciting."

For some players, like [P37], the reasons motivated their play changed. As can be seen in his quote below, it seems that his sense of competence impacted this change:

I became more and more familiar with the controls of the game and I think my confidence increased in every session. So I think in my first session just off of my curiosity I wanted to go to the next session but for the last session I was enthusiastic of coming and playing again. (P37, Interview 4, CG, M)

At the end of the study, some participants ( $N C G=2, C G=8$ ) asked about where they could get LotRO to play. There were several players, more CG than NCG, who were sad because the study was over, and due to graduate school workload or computer capability they could not play on their own computer. [P32] from CG was one of these players. During the last interview, she stated, "Over the course of the game I started liking it more and more... I am little disappointed that I won't be playing anymore because it was an enjoyable experience." Another CG player expressed her feeling of increased familiarity toward the game during the final interview.

[Laughter]... this game [LotRO] became a familiar thing for me now, not a house, not a home but something that is close to me. I was feeling happy when I was thinking about coming here. I was thinking that 'I will play and I will do something'. (P22, Interview 4, CG, F)

In summary, interviews revealed that players showed increased motivational interest toward the game as the gameplay sessions progressed. Players in CG were more willing to come back and play the game than NCG. The social aspect of the game became motivating to many players, both CG and NCG. Experience with the game impacted players' awareness of social aspects and the possibility of socialization, but did not guarantee that players will socialize or play with others.

\section{Discussion}

This study aimed to shed more light on the effects of customization on players' motivation in an extended MMO study. Results showed that participants' motivation changed significantly over the course of the study, which was about ten hours. Customization had a medium size effect on players' motivation levels. Therefore, we accept our hypothesis: Customization will lead to increased motivation.

CG and NCG had similar patterns of change in their motivation over time. Players' motivation fluctuated over the course of four sessions. Players were more motivated to play after the first and the third sessions, compared to the second session. Second session was the first real gameplay session after the tutorial. Participants might have had difficulty with the game, which resulted in a drop in their motivation 
to play. The drop after the fourth session may be attributed to the players' knowledge of the artificial limit created by the end of the study.

Hierarchical linear regressions showed that customization is a significant predictor for players' motivation and can explain 12 to $17 \%$ of the variance in participant's willingness to play the game over the course of four sessions. After the first gameplay session, customization remained a significant predictor after we controlled for other variables that may impact player motivation. This result implies that novice players will be willing to replay a videogame if they are exposed to customization opportunities. In MMOs, players are introduced to more choices in the form of customization as they progress in the game, which may partly explain players' continuing motivation to play these games. Self-Determination Theory (Deci \& Ryan, 1985) suggests that choice is closely related to autonomy, and autonomy is crucial for people's motivation, implying that if people feel control over an activity, they will feel more motivated to come back to do the same activity.

For the first session only, playability was a significant predictor. It was important for participants, who were novice players, to understand the game interface and controls. After they gained enough mastery of controls, playability ceased to be a significant predictor. Ryan et al. (2010) also put forward mastery of controls as an important dimension towards player motivation.

For all sessions, novelty was a significant predictor. This supports the notion of "appealing novelty" (Carroll, 1990, p. 195) in that novelty commands attention and elicits curiosity. As we mentioned in the beginning of the paper, MMOs are long-term games and we may find that the novelty effect fades later in the game. The game world was novel to the players for the first ten hours of the gameplay. Table 3 shows the average ratings of players for their sense of novelty per group. For all sessions, CG reported higher levels of novelty compared to NCG. For CG players, perhaps continuous customization extended and amplified the initial sense of novelty. If they constantly change their gameplay experience through making decisions on multiple aspects of the game, players may be more likely to feel the game being more dynamic and motivating. This will certainly not be true for all players, or for all games, but indicates a fruitful direction for further thought and research.

Sense of control emerged as a statistically significant predictor of motivation after the third session and remained significant after the fourth session. It is likely that players' increased mastery of controls impacted their sense of control. Sense of control, in turn, influenced feelings of autonomy, which then affected their motivation (Ryan et al., 2006).

\section{Limitations}

This study has multiple limitations. Its results may not be fully applicable to other types of virtual environments due to their structural differences, for example in narrative and avatar customization processes. Rozendaal, Keyson, Ridder, \& Craig (2009) found that player engagement is related to the richness of the game (e.g., number of game features available to players) and players' sense of control. MMOs provide players with freedom to choose among many options (e.g., complete quests, engage in combat, explore, socialize). Customization on top of these choices might not have mattered as much for players due to the inherent richness of LotRO. The effect of customization may differ in virtual environments that do not have as many options available to players. Future studies should investigate the effect of customization within other types of games to help generalize motivational effects of customization.

Different types of customization might lead to different psychological experiences (e.g., Kim et al., 2015). In this study, we did not manipulate functional, aesthetic, and usability customization. Instead, participants either could customize everything or nothing. Some types of customization are easier to design than others. Future studies should examine the impact of different types of customization on player motivation.

This study relied on subjective data collected in a lab environment. Although we tried to make the environment as comfortable as possible, it is still a low-fidelity gaming environment for participants. Players were given a choice to continue to play after each session. Still, a monetary reward, no matter how small it is, may impact players' decisions to play. Future studies may conduct online studies and employ data analytics methods to study the relationship between customization and motivation to continue to play. 
Metcalfe, Eich, and Castell (2010) found that people perceive different levels of agency across their lifespans. People in their 20s were very sensitive to when they are and are not in control, and can make refined judgments of agency. Older adults were less sensitive, across the board, to a lack of control. The children were highly sensitive to a lack of control when the external source of the distortion impaired their performance, but they were completely insensitive when the external source helped performance. Therefore, future studies should take age into consideration when examining the relationship between customization and sense of control.

This study was conducted with novice MMO players. The results may not be fully applicable to players of varying expertise. It is reasonable to think that experts may bring dramatically different expectations to their gameplay, their customization practices, and how these impact their relationships with their avatars.

Related to expertise, a longer study may find different results. Although this study involved significant amounts of gameplay, it is likely that as players gain more expertise, the impact of certain types of customization may become more salient and others may become weaker to retain them.

\section{Conclusion}

Results of the current study indicate that being able to customize various aspects of the game increased players' autonomy satisfaction, which increased their willingness to play the game again. This supports previous studies that assert perceived autonomy results in higher levels of intrinsic motivation and enjoyment of games (Przybylski et al., 2010).

From the qualitative data, it was clear that players' autonomy (having more choices and being able to explore) was also related to their sense of competence, which may be facilitated by the leveling mechanics and progression in the game. As players progress, they are provided with more choices, and gameplay also gets more challenging; influencing players' sense of competence. The qualitative findings also indicate the positive relationship between perceived choice, customization and motivation.

Lastly, Wouters, van Nimwegen, van Oostendorp, \& van der Spek (2013)'s meta-analysis showed that there is a gap in the literature on the investigation of user control in serious games. Considering the positive relationship between customization and sense of control, future studies are needed to examine to how different types of customization impact players' experiences in other gaming contexts.

\section{References}

Adinolf, S., \& Turkay, S. (2011). Controlling your game controls: Interface and customization. In Proceedings of the 7th international conference on Games+ Learning + Society Conference (pp. 13-22). ETC Press.

Averill, J. R. (1973). Personal control over aversive stimuli and its relationship to stress. Psychological Bulletin, 80, 286-303. http://dx.doi.org/10.1037/h0034845

Bailey, R., Wise, K., \& Bolls, P. (2009). How avatar customizability affects children's arousal and subjective presence during junk food-sponsored online video games. CyberPsychology \& Behavior, 12, 277-283. http://dx.doi.org/10.1089/cpb.2008.0292

Baranes, A. F., Oudeyer, P.-Y., \& Gottlieb, J. (2014). The effects of task difficulty, novelty and the size of the search space on intrinsically motivated exploration. Frontiers in Neuroscience, 8.

http://dx.doi.org/10.3389/fnins.2014.00317

Bartle, R. A. (2003). Designing virtual worlds. New Riders.

Biederman, I., \& Vessel, E. A. (2006). Perceptual pleasure and the brain: A novel theory explains why the brain craves information and seeks it through the senses. American Scientist, 94, 247-253.

http://dx.doi.org/10.1511/2006.59.995

Bioware. (2011). Star Wars: The Old Republic. [PC Game]. Electronics Arts.

Blizzard. (2004). World of Warcraft. [PC Game]. Vivendi Universal. 
Carroll, N. (1990). The philosophy of horror, or paradoxes of the heart. New York: Routledge.

Choi, D., \& Kim, J. (2004). Why people continue to play online games: In search of critical design factors to increase customer loyalty to online contents. CyberPsychology \& Behavior, 7, 11-34.

http://dx.doi.org/10.1089/109493104322820066

Cordova, D. I., \& Lepper, M.R. (1996). Intrinsic motivation and the process of learning: Beneficial effects of contextualization, personalization, and choice. Journal of Educational Psychology, 19(88), 715-730. http://dx.doi.org/10.1037/0022-0663.88.4.715

Csikszentmihalyi, M. (1975). Beyond boredom and anxiety: Experiencing flow in work and play. San Francisco, CA: Jossey-Bass.

Deci, E. L., \& Ryan, R. M. (1985). Intrinsic motivation and self-determination in human behavior. New York, NY: Plenum Press.

Desurvire, H., Caplan, M., \& Toth, J. A. (2004). Using heuristics to evaluate the playability of games. In CHI'04 extended abstracts on Human factors in computing systems (pp. 1509-1512). ACM.

Dickey, M. D. (2007). Game design and learning: A conjectual analysis of how massively mutliple online role-playing games (MMORPGs) foster intrinsic motivation. Educational Tech Research Development, 55, 253-273. http://dx.doi.org/10.1007/s11423-006-9004-7

Ducheneaut, N., Wen, M.-H., Yee, N., \& Wadley, G. (2009). Body and mind: A Study of avatar personalization in three virtual worlds. In Proceedings of the SIGCHI Conference on Human Factors in Computing Systems (pp. 1151-1160). New York, NY, USA: ACM.

Ducheneaut, N., Yee, N., Nickell, E., \& Moore, R. J. (2006). Alone together? Exploring the social dynamics of massively multiplayer online games. In ACM Conference on Human Factors in Computing Systems (pp.407-416). NY: ACM.

Fischer, P., Kastenmüller, A., \& Greitemeyer, T. (2010). Media violence and the self: The impact of personalized gaming characters in aggressive video games on aggressive behavior. Journal of Experimental Social Psychology, 46, 192-195. http://dx.doi.org/10.1016/j.jesp.2009.06.010

Grodal, T. (2000). Video games and the pleasure of control. In D. Zillman \& P. Vorderer (Eds.), Media entertainment: The psychology of its appeal (pp. 197-213). Mahwah, NJ: Lawrence Erlbaum.

Holm, J., Havukainen, K., \& Arrasvuori, J. (2005). Personalizing game content using audio-visual media. In Proceedings of the 2005 ACM SIGCHI International Conference on Advances in computer entertainment technology (pp. 298-301). ACM.

Hsu, S. H., Lee, F.-L., \& Wu, M.-C. (2005). Designing action games for appealing to buyers. CyberPsychology \& Behavior, 8, 585-591.

Hussain, Z., Williams, G. A., \& Griffiths, M. D. (2015). An exploratory study of the association between online gaming addiction and enjoyment motivations for playing massively multiplayer online role-playing games. Computers in Human Behavior, 50, 221-230. http://dx.doi.org/10.1016/j.chb.2015.03.075

Iyengar, S. S., \& Lepper M. R. (1999). Rethinking the role of choice: A cultural perspective on intrinsic motivation. Journal of Personality \& Social Psychology, 76, 349-66. http://dx.doi.org/10.1037/00223514.76.3.349

Kim, K., Schmierbach, M. G., Bellur, S. Chung, M.-Y., Fraustino, J. D., Dardis, F., \& Ahern, L. (2015). Is it a sense of autonomy, control, or attachment? Exploring the effects of in-game customization on game enjoyment. Computers in Human Behavior, 48, 695-705. http://dx.doi.org/10.1016/j.chb.2015.02.011

Kinzer, C., Hoffman, D., Turkay, S., Chantes, P., Gunbas, N., Dvorkin, T., \& Chaiwinij, A. (2012). The impact of choice and feedback on learning, motivation, and performance in an educational video game. In K. Squire, C. Martin, \& A. Ochsner (Eds.), Proceedings of the Games, Learning, and Society Conference: Vol. 2. (pp. 175-181). Pittsburgh PA: ETC Press. 
Klimmt, C., Hefner, \& Vorderer, P. (2009). The video game experience as "true" identification: A theory of enjoyable alterations of players' self-perception. Communication Theory, 19, 351-373.

http://dx.doi.org/10.1111/j.1468-2885.2009.01347.x

Turbine. (2007). Lord of the Rings Online [PC Game]. Warner Bros. Entertainment Inc.

Mahmassani, H. S., Chen, R. B., Huang, Y., Williams, D., \& Contractor, N. (2010). Time to play? Activity engagement in multiplayer online role-playing games. Transportation Research Record, 2157, 129-137. http://dx.doi.org/10.3141/2157-16

Malone, T. W. (1981). Toward a theory of intrinsically motivating instruction. Cognitive Science, 4, 333381. http://dx.doi.org/10.1207/s15516709cog0504_2

Marathe, S. (2007, May). If you build it, they will come - Or will they? Need for uniqueness and need for control for psychological predictions of customization. Paper presented at the Communication and Technology Division at the 57th Annual Conference of the International Communication Association, San Francisco, CA, USA.

Metcalfe, J., Eich, T. S., \& Castel, A. D. (2010). Metacognition of agency across the lifespan. Cognition, 116, 267-282. http://dx.doi.org/10.1016/j.cognition.2010.05.009

$\mathrm{Ng}$, B. D., \& Wiemer-Hastings, P. (2005). Addiction to the Internet and online gaming. CyberPsychology \& Behavior, 8, 110-113. http://dx.doi.org/10.1089/cpb.2005.8.110

O'Brien, H. L., \& Toms, E. G. (2010). The development and evaluation of a survey to measure user engagement. Journal of the American Society for Information Science and Technology, 61, 50-69. http://dx.doi.org/10.1002/asi.21229

Ondrejka, C. (2004, October). Escaping the gilded cage: User created content and building the metaverse. Paper presented at the Institute for Information Law and Policy Symposium: State of Play: II. New York, NY, USA.

Pace, S. (2004). A grounded theory of the flow experiences of Web users. International Journal of HumanComputer Studies, 60, 327-363. http://dx.doi.org/10.1016/j.ijhcs.2003.08.005

Przybylski, A. K., Rigby, C. S., \& Ryan, R. M. (2010). A motivational model of video game engagement. Review of General Psychology, 14, 154-166. http://dx.doi.org/10.1037/a0019440

Reichheld, F. F., \& Schefter, P. (2000). E-Loyalty. Harvard Business Review, 78(4), 105-113.

Rieber, L. P. (1996). Seriously considering play: Designing interactive learning environments based on the blending of microworlds, simulations, and games. Educational Technology Research \& Development, 44(2), 43-58. http://dx.doi.org/10.1007/BF02300540

Rozendaal, M. C., Keyson, D. V., Ridder, H. de, \& Craig, P. O. (2009). Game feature and expertise effects on experienced richness, control and engagement in game play. AI \& SOCIETY, 24, 123-133. http://dx.doi.org/10.1007/s00146-009-0188-3

Ryan, R. M., \& Deci, E. L. (2000). Self-determination theory and the facilitation of intrinsic motivation, social development and well-being. American Psychologist, 55, 68-78. http://dx.doi.org/10.1037/0003066X.55.1.68

Ryan, R. M., Rigby, C. S., \& Przybylski, A. (2006). The motivational pull of video games: A selfdetermination theory approach. Motivation and Emotion, 30, 347-363.

Ryan, R. M., Mims, V., \& Koestner, R. (1983). Relation of reward contingency and interpersonal context to intrinsic motivation: A review and test using cognitive evaluation theory. Journal of Personality and Social Psychology, 45, 736-750. http://dx.doi.org/10.1037/0022-3514.45.4.736

Sony Computer Entertainment. (2008). Little Big Planet. [PC Game]. 
Stafford, T., Stafford, M. R., \& Schkade, L. L. (2004). Determining uses and gratifications for the Internet. Decision Sciences, 35, 259-288. http://dx.doi.org/10.1111/j.00117315.2004.02524.x

Sweetsner, P., \& Wyeth, P. (2005). GameFlow: A model for evaluating player enjoyment in Games. Computers in Entertainment, 3(3), Article 3A.

Teng, C.-I. (2010). Customization, immersion satisfaction, and online gamer loyalty. Computers in Human Behavior, 26, 1547-1554. http://dx.doi.org/10.1016/j.chb.2010.05.029

Trepte, S., \& Reinecke, L. (2010). Avatar creation and video game enjoyment: Effects of life satisfaction, game competitiveness, and identification with the avatar. Journal of Media Psychology: Theories, Methods, and Applications, 22, 171-184. http://dx.doi.org/10.1027/1864-1105/a000022

Turkay, S., \& Adinolf, S. (2010a). Enjoyment of customization in multi user online games: A survey study with World of Warcraft and City of Heroes/Villains players. In Proceedings of World Conference on Educational Multimedia, Hypermedia and Telecommunications 2010 (pp. 592-601). Chesapeake, VA: AACE.

Turkay, S., \& Adinolf, S. (2010b). Free to be me: A survey study on customization with World of Warcraft and City Of Heroes/Villains players. Procedia - Social and Behavioral Sciences, 2, 1840-1845.

http://dx.doi.org/10.1016/j.sbspro.2010.03.995

Turkay, S., \& Kinzer, C. K. (2014). The effects of avatar-based customization on player identification. International Journal of Gaming and Computer-Mediated Simulations, 6(1), 1-25.

http://dx.doi.org/10.4018/ijgcms.2014010101

Turkle, S. (1995). Life on the screen: Identity in the age of the Internet. New York, NY: Simon \& Schuster.

Walther, J. B., van der Heide, B., Kim, S. Y., Westerman, D., \& Tong, S. T. (2008). The role of friends' behavior on evaluations of individuals' Facebook profiles: Are we known by the company we keep? Human Communication Research, 34, 28-49. http://dx.doi.org/10.1111/j.1468-2958.2007.00312.x

Wouters, P., van Nimwegen, C., van Oostendorp, H., \& van der Spek, E. D. (2013). A meta-analysis of the cognitive and motivational effects of serious games. Journal of Educational Psychology, 105, 249-265.

http://dx.doi.org/10.1037/a0031311

Yee, N. (2006). The demographics, motivations and derived experiences of users in massively multiplayer online graphical environments. PRESENCE: Teleoperators and Virtual Environments, 15, 309-329.

http://dx.doi.org/10.1162/pres.15.3.309

\section{Appendix}

Table A1. Correlations Between Variables in the Regression Model for Session 1.

\begin{tabular}{llllll}
\hline & $\mathbf{1}$ & $\mathbf{2}$ & $\mathbf{3}$ & $\mathbf{4}$ & $\mathbf{5}$ \\
\hline 1. Customization & 1 & & & & \\
2. Motivation & $.374^{* *}$ & 1 & & & \\
3. Novelty & $.320^{* *}$ & $.527^{* * *}$ & 1 & $.363^{* *}$ & 1 \\
4. Perceived Playability & .121 & $.284^{*}$ & $.385^{* *}$ & $.537^{* * *}$ & 1 \\
5. Perceived Control & .202 & $.247^{*}$ & & \\
\hline
\end{tabular}

Note: ${ }^{*} p<.05 ;{ }^{* *} p<.01 ;{ }^{* * *} p<.001$ 
Table A2. Correlations Between Variables in the Regression Model for Session 2.

\begin{tabular}{llllll}
\hline & $\mathbf{1}$ & $\mathbf{2}$ & $\mathbf{3}$ & $\mathbf{4}$ & $\mathbf{5}$ \\
\hline 1. Customization & 1 & & & & \\
2. Motivation & $.344^{* *}$ & 1 & & & \\
3. Novelty & $.320^{* *}$ & $.650^{* * *}$ & 1 & & \\
4. Perceived Playability & .121 & $.296^{*}$ & $.363^{* *}$ & 1 & $.385^{* *}$ \\
5. Perceived Control & .202 & $.303^{*}$ & $.537^{* * *}$ & 1 \\
\hline
\end{tabular}

Note: $p<.05 ;{ }^{* *} p<.01 ;{ }^{* * *} p<.001$

Table A3. Correlations Between Variables in the Regression Model for Session 3.

\begin{tabular}{llllll}
\hline & $\mathbf{1}$ & $\mathbf{2}$ & $\mathbf{3}$ & $\mathbf{4}$ & $\mathbf{5}$ \\
\hline 1. Customization & 1 & & & & \\
2. Motivation & $.411^{* *}$ & 1 & & & \\
3. Novelty & $.403^{* *}$ & $.618^{* * *}$ & 1 & & \\
4. Perceived Playability & .13 & $.371^{* *}$ & .125 & 1 & $.659^{* * *}$ \\
5. Perceived Control & $.356^{* *}$ & $.581^{* * *}$ & $.350^{* *}$ & 1 \\
\hline
\end{tabular}

Note: $p<.05 ;{ }^{* *} p<.01 ;{ }^{* * *} p<.001$

Table A4. Correlations Between Variables in the Regression Model for Session 4.

\begin{tabular}{llllll}
\hline & $\mathbf{1}$ & $\mathbf{2}$ & $\mathbf{3}$ & $\mathbf{4}$ & $\mathbf{5}$ \\
\hline 1. Customization & 1 & & & & \\
2. Motivation & $.518^{* * *}$ & 1 & & & \\
3. Novelty & $.378^{* *}$ & $.738^{* * *}$ & 1 & & \\
4. Perceived Playability & $.395^{* *}$ & $.500^{* * *}$ & $.453^{* * *}$ & 1 & \\
5. Perceived Control & $.276^{*}$ & $.576^{* * *}$ & $.519^{* * *}$ & $.612^{* * *}$ & 1 \\
\hline
\end{tabular}

Note: $p<.05 ;{ }^{* *} p<.01 ;{ }^{* * *} p<.001$

Table A5. Summary of Hierarchical Regression Analysis for Variables Predicting Motivation at the End of Session 1.

\begin{tabular}{|c|c|c|c|c|c|c|}
\hline & $B$ & $S E$ & $\bar{B}$ & $\bar{t}$ & $R^{2}$ & $\Delta R^{2}$ \\
\hline Step 1 & & & & & .14 & \\
\hline Constant & 3.07 & .64 & & 4.83 & & \\
\hline Customization & 1.29 & .40 & $.37 * *$ & 3.20 & & \\
\hline Step 2 & & & & & .44 & .30 \\
\hline Constant & -1.38 & 1.06 & & -1.30 & & \\
\hline Customization & .83 & .36 & $.24^{*}$ & 2.31 & & \\
\hline Novelty & .85 & .21 & $.44^{* *}$ & 4.00 & & \\
\hline Perceived Playability & .90 & .36 & $.32 *$ & 2.48 & & \\
\hline Perceived Control & -.19 & .25 & -.10 & -.73 & & \\
\hline
\end{tabular}

Note: ${ }^{*} p<.05 ;{ }^{* *} p<.01 ;{ }^{* * *} p<.001$ 
Table A6. Summary of Hierarchical Regression Analysis for Variables Predicting Motivation at the End of Session 2.

\begin{tabular}{|c|c|c|c|c|c|c|}
\hline & $B$ & $S E$ & $\bar{b}$ & $\bar{t}$ & $R^{2}$ & $\Delta R^{2}$ \\
\hline Step 1 & & & & & .12 & \\
\hline Constant & 2.46 & .57 & & 4.29 & & \\
\hline Customization & 1.06 & .36 & $.34 * *$ & 2.93 & & \\
\hline Step 2 & & & & & .45 & .33 \\
\hline Constant & .02 & .82 & & .03 & & \\
\hline Customization & .46 & .31 & .14 & 1.48 & & \\
\hline Novelty & .87 & .17 & $.57 * * *$ & 5.24 & & \\
\hline Perceived Playability & .14 & .27 & .06 & .51 & & \\
\hline Perceived Control & .04 & .20 & .02 & .18 & & \\
\hline
\end{tabular}

Note: ${ }^{*} p<.05 ;{ }^{* *} p<.01 ;{ }^{* * *} p<.001$

Table A7. Summary of Hierarchical Regression Analysis for Variables Predicting Motivation at the End of Session 3.

\begin{tabular}{|c|c|c|c|c|c|c|}
\hline & $B$ & $S E$ & B & $t$ & $R^{2}$ & $\Delta R^{2}$ \\
\hline Step 1 & & & & & .17 & \\
\hline Constant & 3.39 & .54 & & 6.24 & & \\
\hline Customization & 1.24 & .34 & $.41^{* *}$ & 3.61 & & \\
\hline Step 2 & & & & & .54 & .37 \\
\hline Constant & .48 & .85 & & .56 & & \\
\hline Customization & .30 & .30 & .10 & 1.02 & & \\
\hline Novelty & .65 & .14 & .45 & $4.60 * * *$ & & \\
\hline Perceived Playability & .21 & .29 & .08 & .71 & & \\
\hline Perceived Control & .47 & .18 & .33 & $2.62^{* *}$ & & \\
\hline
\end{tabular}

Note: ${ }^{*} p<.05 ;{ }^{* *} p<.01 ;{ }^{* * *} p<.001$

Table A8. Summary of Hierarchical Regression Analysis for Variables Predicting Motivation at the End of Session 4.

\begin{tabular}{|c|c|c|c|c|c|c|}
\hline & $B$ & $S E$ & B & $t$ & $R^{2}$ & $\Delta R^{2}$ \\
\hline Step 1 & & & & & .27 & \\
\hline Constant & 1.88 & .39 & & 3.51 & & \\
\hline Customization & 1.22 & .39 & $.52 * *$ & 3.52 & & \\
\hline Step 2 & & & & & 65 & .38 \\
\hline Constant & -2.17 & .77 & & -2.81 & & \\
\hline Customization & .91 & .31 & .25 & $2.95^{* *}$ & & \\
\hline Novelty & .93 & .17 & .51 & $5.53 * * *$ & & \\
\hline Perceived Playability & .10 & .29 & .03 & .33 & & \\
\hline Perceived Control & .40 & .19 & .22 & $2.16^{*}$ & & \\
\hline
\end{tabular}

Note: ${ }^{*} p<.05 ;{ }^{* *} p<.01 ;{ }^{* * *} p<.001$ 


\section{Correspondence to:}

Selen Turkay

Harvard University

125 Mt Auburn Street

Office \# 418

Cambridge, MA 02138

Email: selen_turkay(at)harvard.edu

\section{About authors}

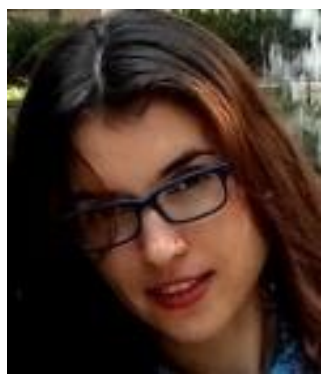

Selen Turkay is a research fellow at Harvard Initiative for Learning and Teaching (HILT). Her research interests include design of personalized, interactive, and collaborative learning environments in particular gaming and virtual worlds.

Specifically, she studies the effects of design choices on learning agency and outcomes, as well as learner experiences including engagement and motivation. Her research approach is a synthesis of mixed methods, qualitative to quantitative (focus groups, case studies, diary studies, content analysis, surveys, eye-tracking, true experiments). Selen earned her Ed.D. in Instructional Technology and Media at Teachers College Columbia University.

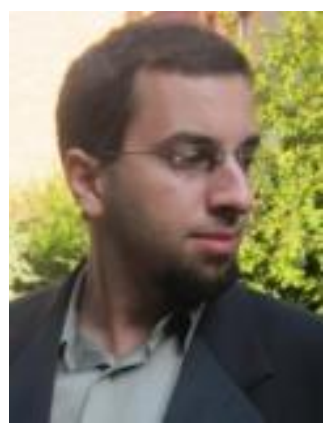

Sonam Adinolf works at the Massachusetts Institute of Technology. He has been performing games research for 8 years. He has predominantly focused on virtual worlds, with some exploration of collectible card games as well. He finds the dynamics in games that affect enjoyment and socialization to be fascinating. 